\title{
Nationwide Statistical Analysis of Lymphoid Malignancies in Korea
}



${ }^{1}$ Center for Hematologic Malignancy and ${ }^{2}$ Center for Pediatric Oncology, Research Institute and Hospital, National Cancer Center, Goyang, ${ }^{3}$ Cancer Registration and Statistics Branch, National Cancer Center, Goyang, Departments of ${ }^{4}$ System Cancer Science and ${ }^{5}$ Cancer Control and Policy, Graduate School of Cancer Science and Policy, National Cancer Center, Goyang, Korea
Correspondence: Hyeon-Seok Eom, MD, PhD Center for Hematologic Malignancy, Research Institute and Hospital,

National Cancer Center, 323 Ilsan-ro, Ilsandong-gu, Goyang 10408, Korea Tel: $82-31-920-2402$

Fax: 82-31-920-1163

E-mail: hseom@ncc.re.kr

Co-correspondence: Young-Joo Won, $\mathrm{PhD}$ Cancer Registration and Statistics Branch, National Cancer Center, 323 Ilsan-ro, Ilsandong-gu, Goyang 10408, Korea Tel: 82-31-920-2015

Fax: 82-31-920-2179

E-mail: astra67@ncc.re.kr

Received February 22, 2017

Accepted March 20, 2017

Published Online March 30, 2017

\section{Purpose}

Regional differences in the incidence of lymphoid malignancies have been reported worldwide, but there has been no large-scale epidemiologic analysis in Korea. The aim of this study was to provide a nationwide population-based statistical analysis of Korean patients with lymphoid malignancies.

\section{Materials and Methods}

The Korea Central Cancer Registry analyzed the incidence and survival of patients with lymphoid malignancies from the Korean National Cancer Incidence Database. Diseases were grouped by clinically relevant categories based on the 2008 World Health Organization classification.

\section{Results}

Overall 65,948 lymphoid diseases were identified between 1999 and 2012. The incidence of most subtypes increased with age, except for precursor cell neoplasms. Male predominance (male:female ratio=1.28:1) was observed. In 2012, annual age-standardized incidence rates per 100,000 persons of Hodgkin's lymphoma, mature B-cell neoplasm, mature T/natural killer (NK)-cell neoplasm, and precursor cell neoplasm were 0.46, 6.60, 0.95, and 1.50, respectively, and they increased yearly from 1999. Composite Hodgkin's and non-Hodgkin's lymphomas were extremely rare. Survival improvement estimated using 5-year relative survival rate was observed in patients with Hodgkin's lymphoma (71.1\%83.0\%), diffuse large B-cell lymphoma (49.5\%-61.5\%), plasma cell neoplasms (20.2\%36.9\%), and lymphoblastic lymphoma/leukemia (41.5\%-56.3\%) between 1993 and 2012. However, survival rates of T/NK-cell lymphoma (excluding cutaneous T-cell lymphoma) ranged from $40.5 \%-43.5 \%$ during the study period. Survival rates decreased with age in most subtypes.

\section{Conclusion}

This report presented the subtype-specific statistical analysis of lymphoid malignancies in the Korean population, showing increasing incidences and survival rates in most subtypes.

\author{
Key words \\ Epidemiology, Incidence, Survival, Hematologic neoplasms, \\ Republic of Korea
}




\section{Introduction}

Lymphoid malignancies are a diverse group of neoplasms with different clinical presentations, histology, and biology. They are classified by the morphology, immunophenotype, cytogenetics, and clinical characteristics. The etiology of lymphoid neoplasms is not fully understood. Thus, combining an epidemiologic study with a biological study is helpful for understanding the pathogenesis of each disease.

Different incidences of lymphoid malignancies between regions have been reported [1]. Asian countries have been known to show a relatively lower incidence than the other countries in North America and Europe. In terms of the subtypes of lymphoid malignancies, it also varies in each region. For example, Asian populations show a higher incidence of mature T/natural killer (NK)-cell lymphoma and extranodal marginal zone B-cell lymphoma of mucosa-associated lymphoid tissue type (mucosa-associated lymphoid tissue lymphoma), in contrast, Western population show higher incidence of follicular lymphoma and chronic lymphocytic leukemia (CLL) $[2,3]$. The distribution of lymphoma-associated viruses such as Epstein-Barr virus and human T-lymphoblastic virus-1 has been proposed as a risk factor for the high incidence of specific subtypes of mature T/NK-cell lymphoma in Asian people, but genetic factors may also affect the incidence $[4,5]$.

The classification of hematologic malignancies mainly focused on morphologic and immunophenotypic characteristics before 1990s [6-8], but it has been modified to include cytogenetic characteristics which provide an improved understanding of tumor pathogenesis. The most recent classification of diseases for oncology, International Classification of Diseases for Oncology, third edition (ICD-O-3) was published in 2000 [9] and updated in 2013 to include the changes from the World Health Organization (WHO) classification published in 2008 [2]. Recent cancer registry studies have adopted this ICD-O-3, because it more accurately reflects our recent understanding of these diseases $[10,11]$.

We have published nationwide statistical analyses of hematologic malignancies based on the Korea Central Cancer Registry (KCCR) in 2012 [12]. However, the data was not based on the ICD-O-3 classification. Therefore, to understand the comprehensive incidence and survival of lymphoid malignancies in Korea, we conducted present study with available ICD-O-3 data from the KCCR.

\section{Materials and Methods}

The Korean Ministry of Health and Welfare started the KCCR, a nationwide hospital-based cancer registry in 1980. In 1999, the KCCR expanded to include the entire population in the population-based cancer registry program. Incidence data on lymphoid malignancies between 1999 and 2012 was obtained from the Korean National Cancer Incidence Database (KNCIDB).

The classification of lymphoid malignancies was categorized to account for incidence and clinical characteristics based on the ICD-O-3 [9]. The codes for lymphoid malignancies were grouped into five clinically relevant categories based on the 2008 WHO classification [2]: Hodgkin's lymphoma (HL), mature B-cell neoplasms, mature T-cell and NK-cell neoplasm, precursor cell neoplasm, and unknown type of lymphoid neoplasm (S1 Table).

The crude incidence rates (CR) and age-specific incidence rates of each subtype of lymphoid malignancy were calculated. The CR per 100,000 persons was calculated as an incidence rate based on the frequency of the disease in the entire population by dividing the total number of events $(N)$ by the total number of person-year of observation $(P)$ and multiplying the result by 100,000 . The age-specific incidence rates per 100,000 within an age group $(i)$ were calculated by dividing the number of incident cases observed in the age group $\left(N_{i}\right)$ by the number of corresponding person-year of observation $\left(P_{i}\right)$ and multiplying the result by 100,000 . Age-standardized incidence rates (ASRs), a weighted average of crude age-specific rates, were calculated using the Segi's world standard population [13]. Changes in the annual ASRs were examined by calculating the annual percentage change (APC) over a time period as $(\exp (b)-1) \times 100$, where $b$ is the slope of the regression of $\log (\mathrm{ASR})$ on a calendar year using the following linear regression equation: $\mathrm{E}(\log (\mathrm{ASR}) \mid$ year $)=a+b$ year [14]

For the survival analyses, cases that were diagnosed as lymphoid malignancies and have available data in the KNCIDB between 1993 and 2012 were included. The patient status was followed until December 31, 2013. The relative survival rate (RSR) was estimated by comparing the observed survival of cancer patients with the expected survival of the general population [15]. Five-year RSR was calculated based on the Ederer II method using the algorithm created by Paul Dickman in SAS [16,17]. All analyses were performed using SAS ver. 9.2 (SAS Institute Inc., Cary, NC). 


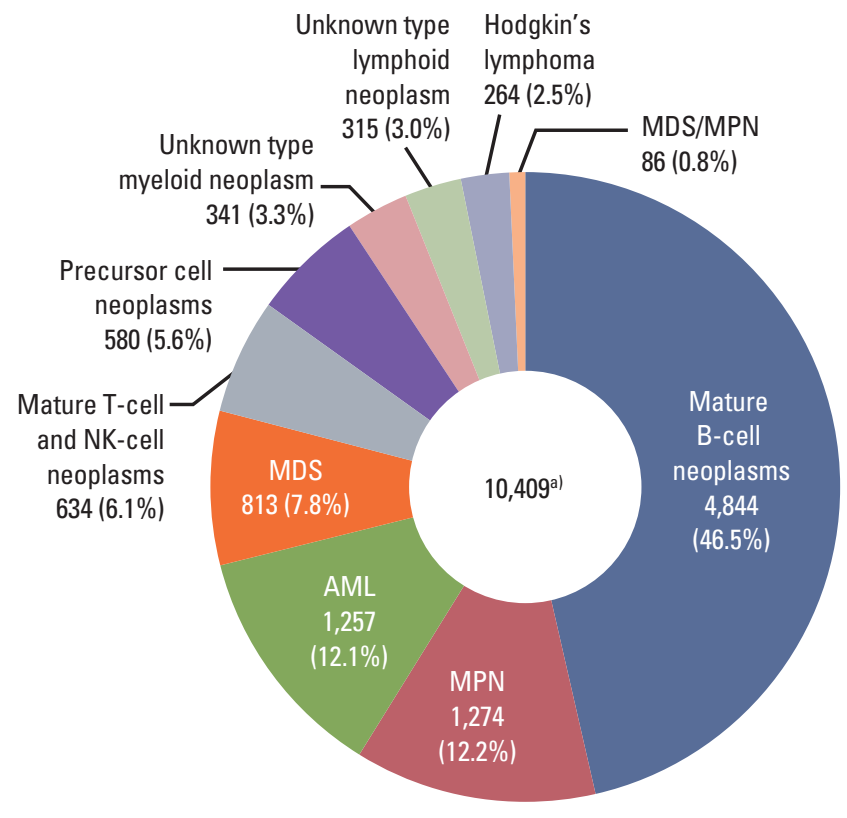

Hematologic malignancies: both sexes



Lymphoid malignancies: men

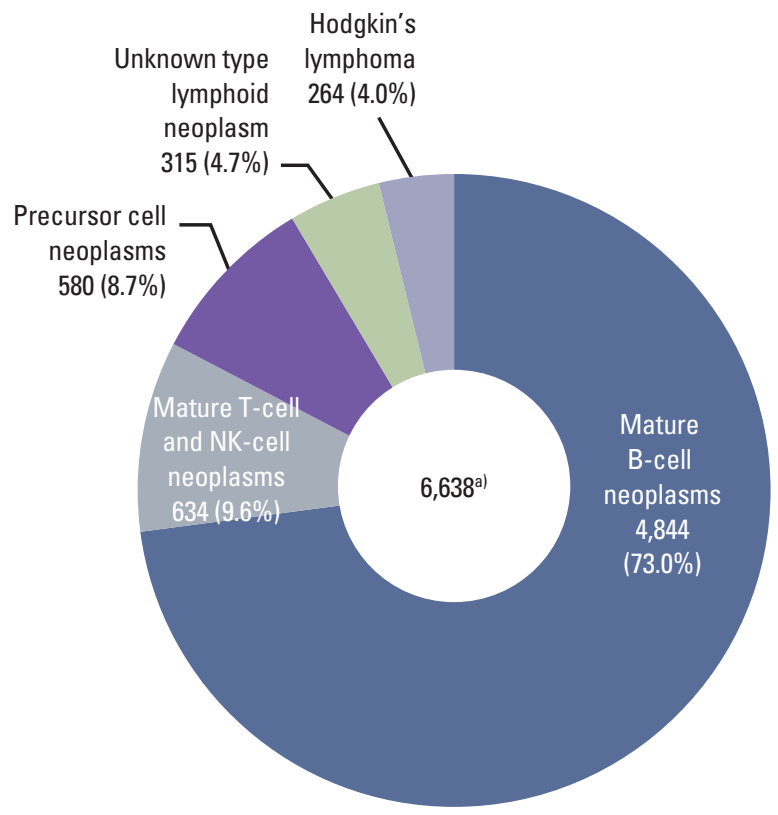

Lymphoid malignancies: both sexes



Lymphoid malignancies: women

Fig. 1. Incident cases of lymphoid malignancies in Korea, 2012. NK, natural killer; MDS, myelodysplastic syndrome; AML,


lymphoma. 




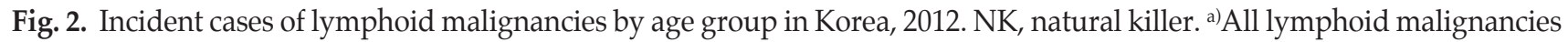
include one case of composite Hodgkin's and non-Hodgkin's lymphoma.

\section{Results}

\section{Incidences of lymphoid malignancies in 2012}

A total of 10,409 cases of hematologic malignancies occurred in 2012, including 6,638 lymphoid malignancies (63.8\%) (3,732 men and 2,906 women, male:female ratio=1.28:1) (Fig. 1). This means that the proportions of lymphoid malignancy were $3.3 \%$ and $2.6 \%$ of all cancers in men and women, respectively. Among all lymphoid malignancies in men, mature B-cell neoplasms $(71.8 \%)$ were the most frequent, followed by mature T-cell and NK-cell neoplasms (10.5\%), and precursor cell neoplasms $(8.7 \%)$. In women, mature B-cell neoplasms $(74.5 \%)$ were the most frequent, followed by precursor cell neoplasms $(8.8 \%)$, and mature T-cell and NK-cell neoplasms (8.4\%).

Patients with aged between 70 and 79 years the highest incidence of lymphoid malignancies in 2012, followed by those aged 50 to 59 years, and then 60 to 69 years (Fig. 2). The precursor cell neoplasms were the most prevalent disease type in patients aged group 0-19 years, whereas mature B-cell neoplasms were the most prevalent in those aged more than 20 years.

\section{Changes in incidences of lymphoid malignancies between 1999 and 2012}

The incident cases of each subtype of lymphoid malignancies and trends in CR and ASR between 1999 and 2012 are shown in Table 1. During the study period, 65,948 lymphoid malignancies were registered. The overall ASR of all lymphoid malignancies increased from 6.9 to 9.9 during the study period. The APC was 3.2\% between 1999 and 2012, and it was statistically significant. The ASRs increased from 0.24 to 0.46 in HL (APC, 5.0\%; $\mathrm{p}<0.05)$, from 3.41 to 6.60 in mature B-cell neoplasm (APC, $5.6 \% ; \mathrm{p}<0.05$ ), from 0.47 to 0.95 in mature T-cell and NK-cell neoplasm (APC, 6.6\%; $\mathrm{p}<0.05$ ), and from 1.33 to 1.50 in precursor cell neoplasm (APC, $1.4 \% ; \mathrm{p}<0.05)$. The ASR of cases categorized as "unknown type lymphoid neoplasm" decreased from 1.44 to 0.41 (APC, $-9.3 \%$; $\mathrm{p}<0.05$ ).

\section{Estimated RSRs of lymphoid malignancies}

The 5-year RSRs of patients with lymphoid malignancies in 5-year intervals (1993-1997, 1998-2002, 2003-2007, and 20082012) are shown in Table 2. HL was associated with better survival than the other disease categories. Decreasing survival with age was observed in most disease types of lymphoid malignancies, with poor prognoses in elderly patients. Especially 





$\frac{u}{4}$





ปั้ ம

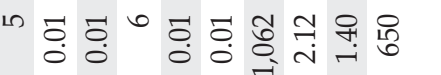

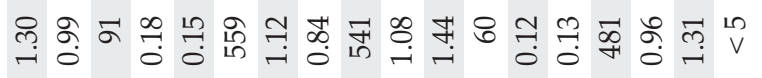

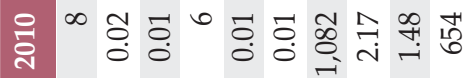

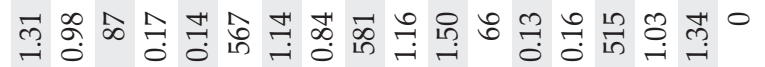



龸

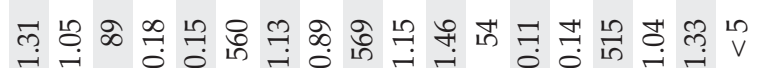



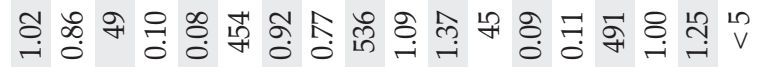



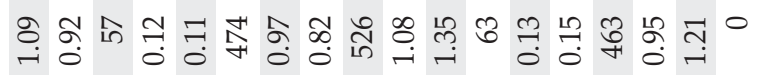
(ृ)

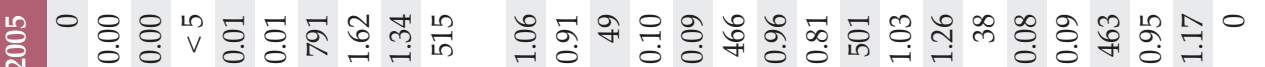

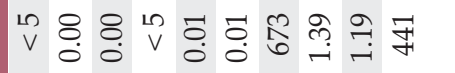

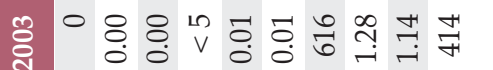
Бू。

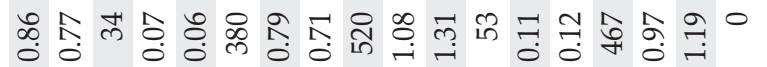
ఫ్

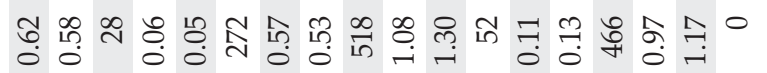



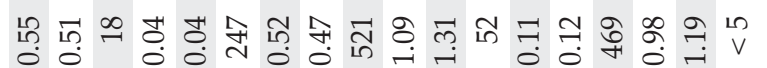

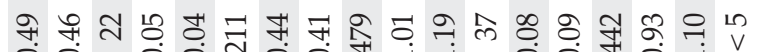

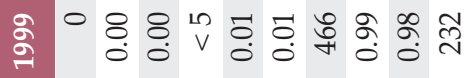

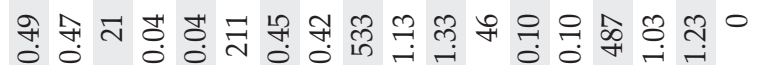


ભ

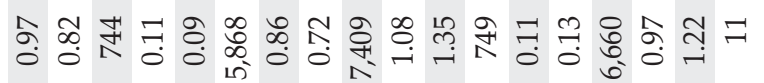

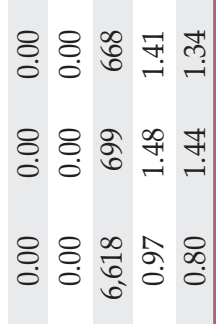

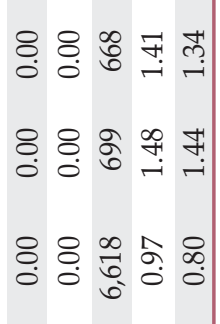
离



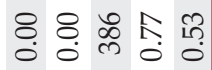
8. 8. त्र

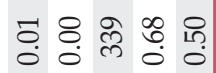

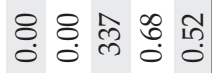

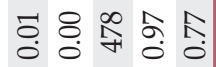

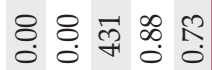

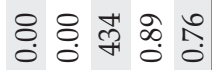



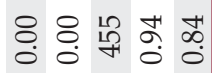

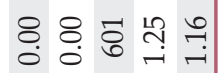
:융 :





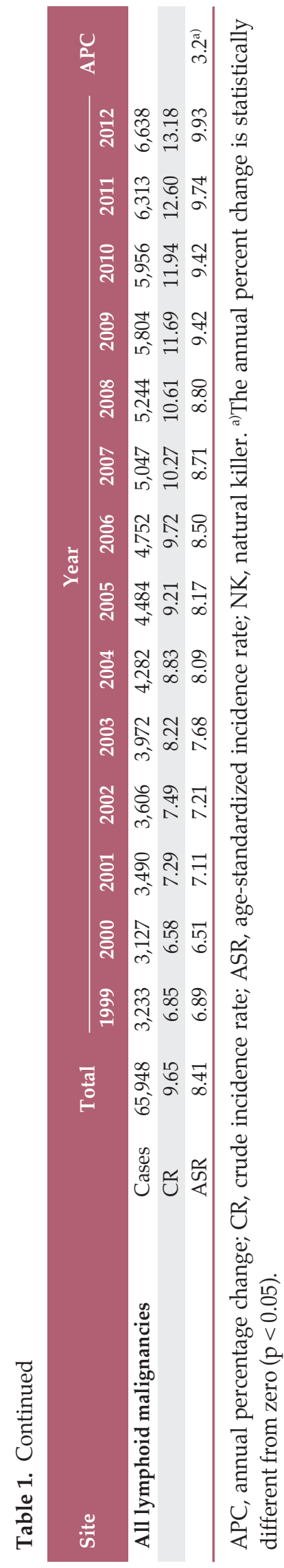

in patients with precursor cell neoplasms, abrupt decrease in survival rates were observed between pediatric patients (aged 0-14 years), adolescents and young adults (aged 15-34 years), and adults (aged 35 years or more).

\section{Changes in the RSRs by major subtypes}

The 5-year RSRs of patients with lymphoid malignancies continually increased from 1993 to 2012, from $45.3 \%$ to $61.7 \%$, with an increment of $16.4 \%$ between these years. The 5 -year RSR for most lymphoid malignancies was improved: from $71.1 \%$ to $83.0 \%$ in $\mathrm{HL}$, from $42.8 \%$ to $63.8 \%$ in mature B-cell neoplasms, and from $41.5 \%$ to $56.3 \%$ in precursor cell neoplasms.

Trends in the RSRs of several major subtypes that are clinically important and accessible in our database are shown in Fig. 3. Yearly improvement of survival outcome was observed in $\mathrm{HL}$, diffuse large B-cell lymphoma (DLBCL), multiple myeloma (MM), lymphoblastic lymphoma, and acute lymphoblastic leukemia. However, survival improvement was not evident in peripheral T-cell lymphomas or extranodal NK/ T-cell lymphomas between 1993 and 2012.

\section{Discussion}

Here, we presented the first comprehensive epidemiologic analysis for lymphoid malignancies in the Korean population. The incidence of lymphoid malignancies increased yearly between 1999 and 2012. In most subtypes except precursor cell neoplasms, the incidences in adults and elderly patients were higher than those in pediatric patients. Relative survival improved during the study period in lymphoid malignancies. However, poor survival outcomes in elderly patients were observed in most subtypes except in indolent diseases such as marginal zone lymphoma.

The incidence of most subtypes in Korea was low, with an ASR less than one per 100,000 except for DLBCL (2.34) and plasma cell neoplasms (1.30). This incidence is quite low compared to data from other countries as we expected based on previous reports of differences in incidences of lymphoid malignancies between countries or ethnic groups (Table 3) $[11,14,18,19]$. The incidence of several subtypes, including follicular lymphoma (ASR, 0.18) and CLL (ASR, 0.18), is lower in Korea than in Western countries. In contrast, the incidence of extranodal NK/T-cell lymphoma, nasal type was relatively high (ASR, 0.22). CLL/small lymphocytic lymphoma (SLL) is the second most common subtype of mature B-cell malignancies in Europe (26\%); however, it is rare in Korea $(3.4 \%)$. Follicular lymphoma was also rare in Korea 
育

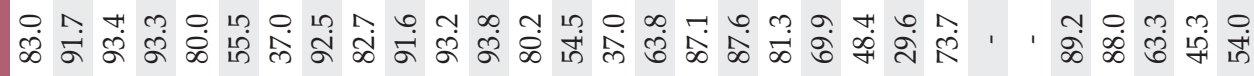

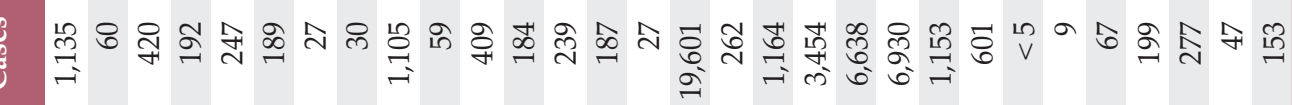


(4)

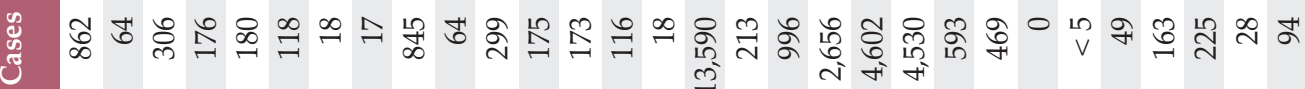

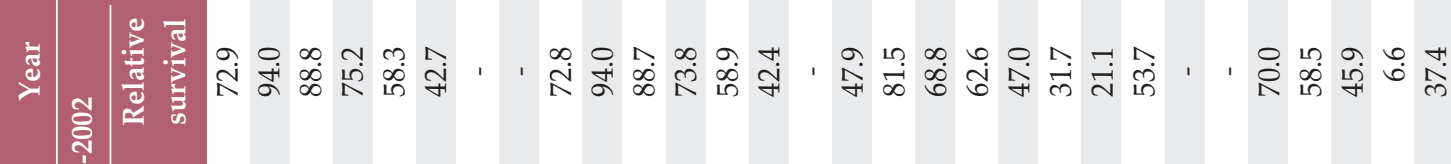

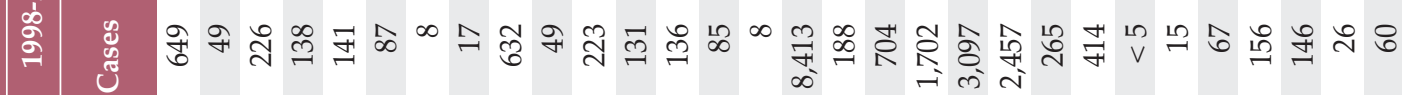

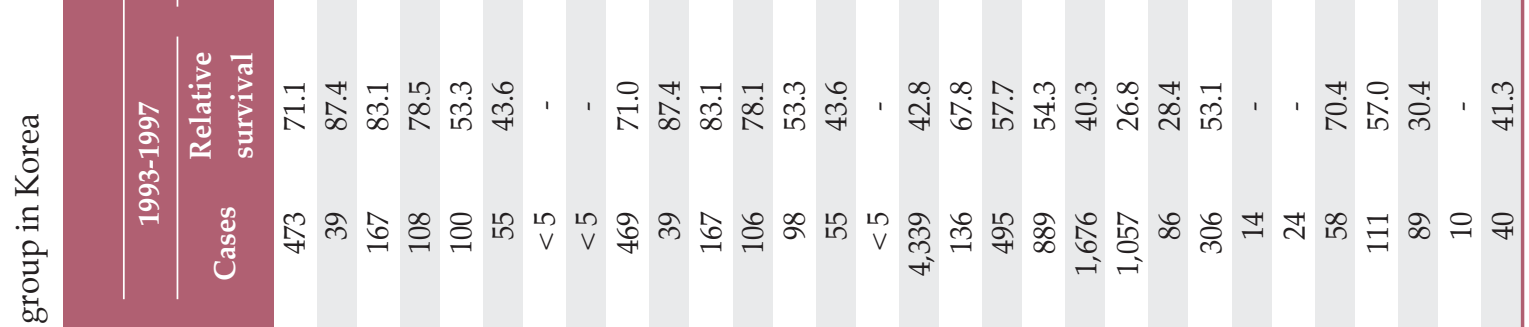
$\underset{\substack{\infty \\ \infty}}{\infty}$ 宓

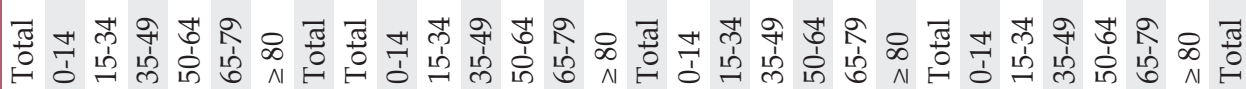
药

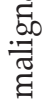
둥 을 突 尊 (5) 产 艺 ปี 这 $\forall$ O

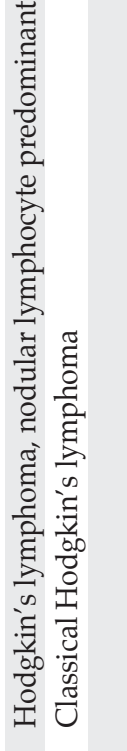

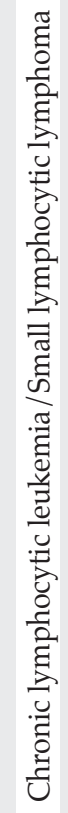






言

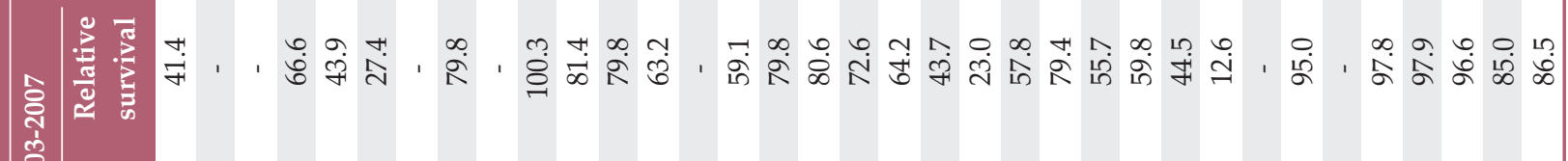

总

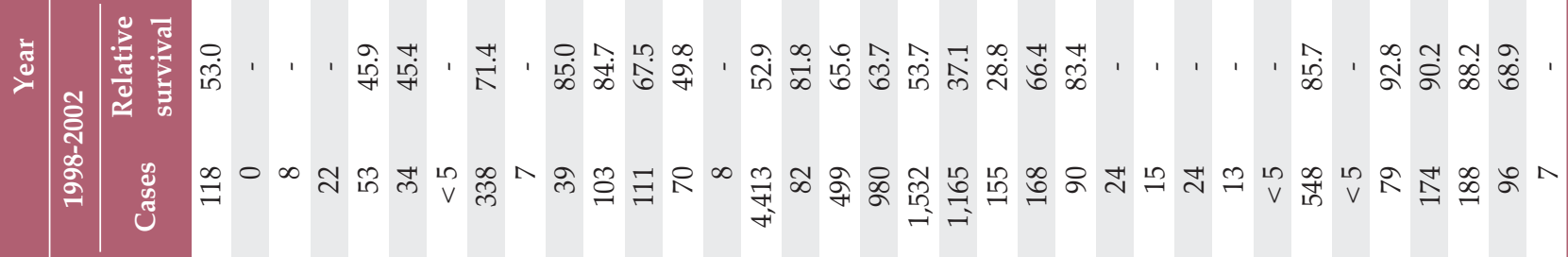

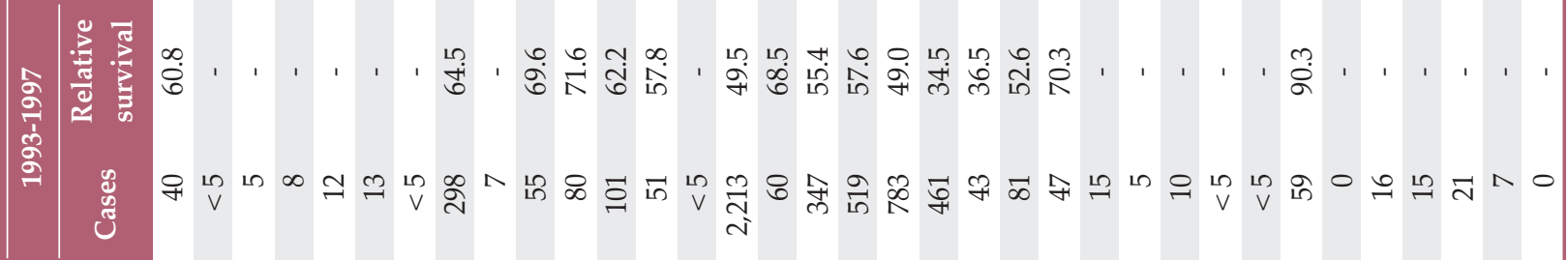



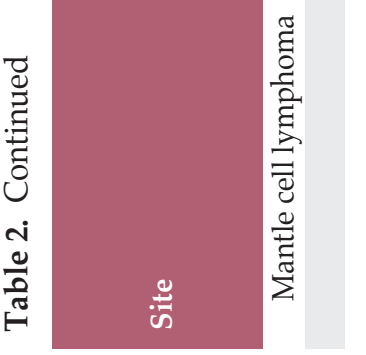




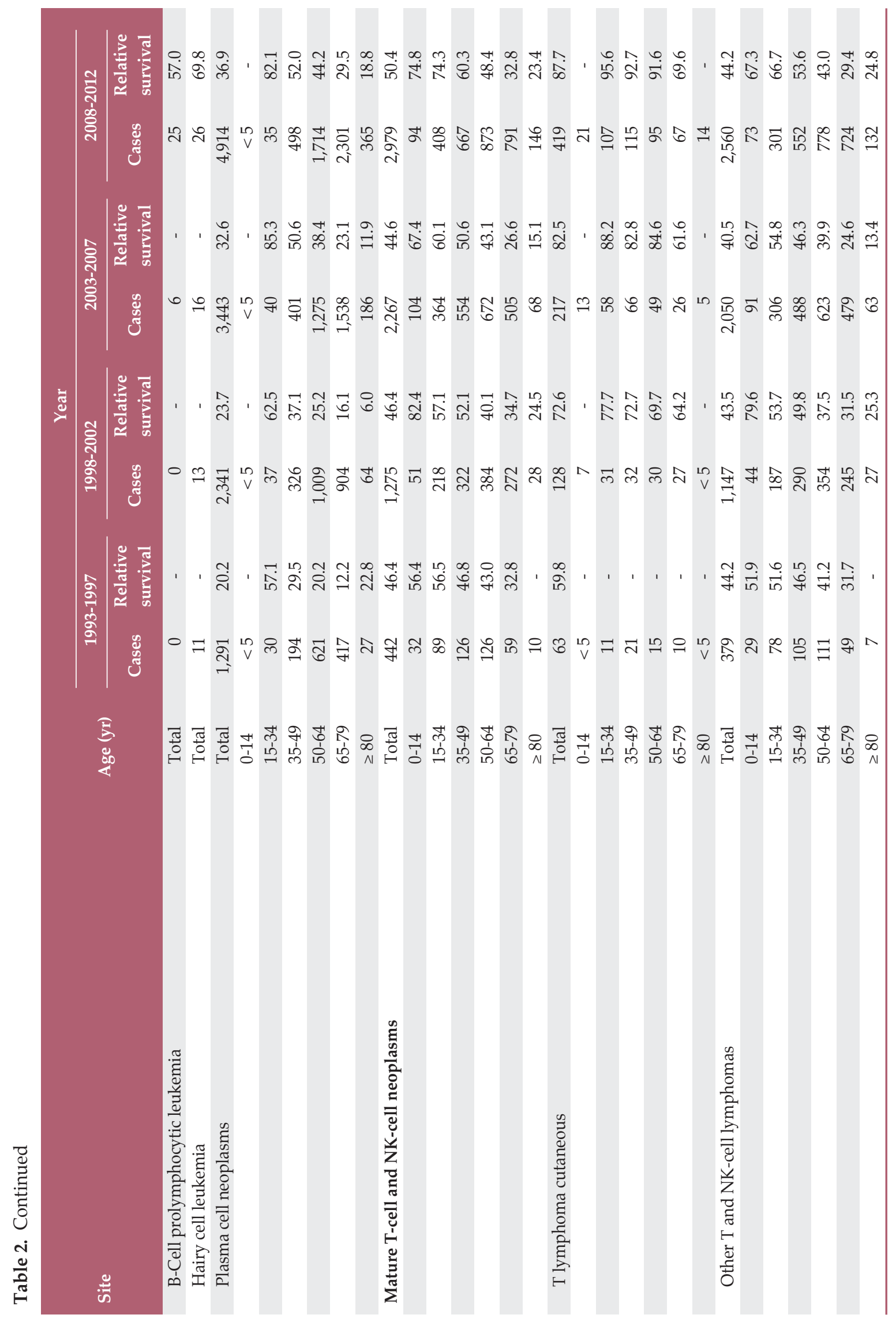




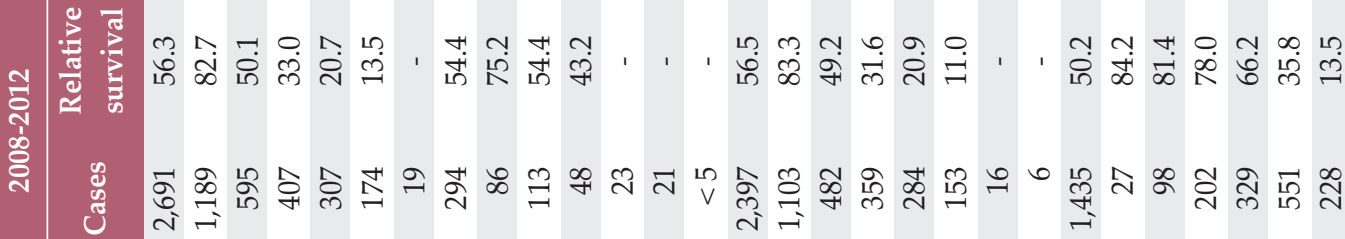

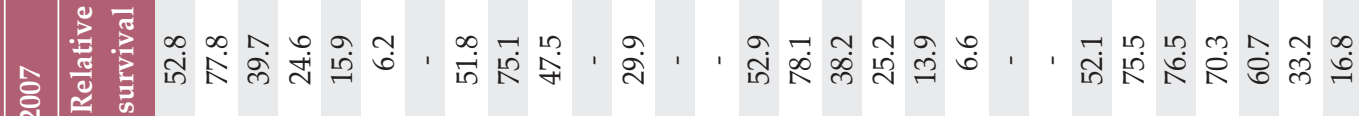

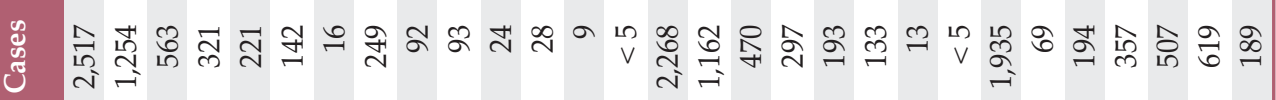
ل्र נֶ

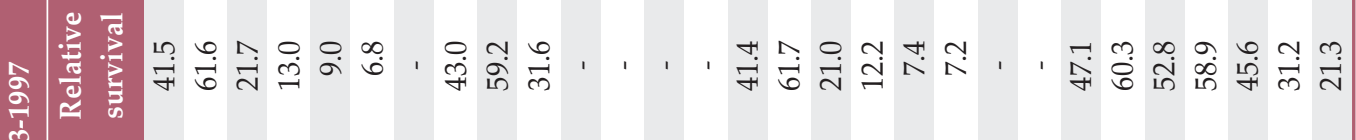

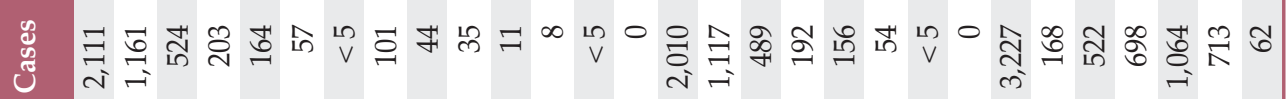

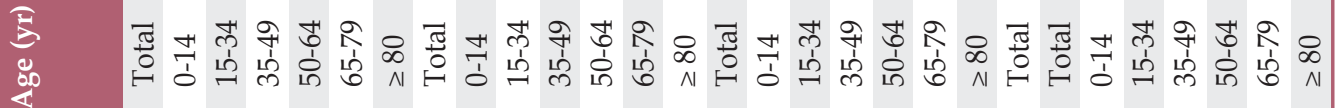

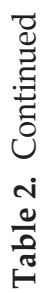

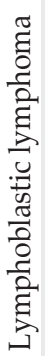

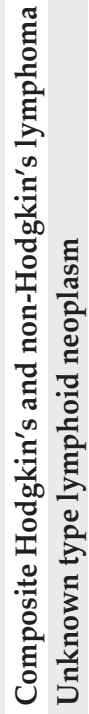






compared to in European countries (3.4\% vs. $11 \%$ of mature B-cell malignancies) [11]. The proportions of CLL/SLL and follicular lymphoma among B-cell non-Hodgkin's lymphoma (NHL) in the United States were $19.6 \%$ and $12.3 \%$, respectively [14]. Although we cannot directly compare the ASRs from our data with those of other registry-based incidences, there are subtype-specific differences in the Korean population compared to foreign data. An increasing trend in the incidence of HL and NHL was observed in Korea, which is similar to Japan [19], but not the United States.

Comprehensive subtype-specific analysis in Asia is limited so far. A recent study performed in Hong Kong showed differences between Hong Kong and the United States [18]. The authors compared the incidences of lymphoid malignancies between the East Asian and white populations from Surveillance, Epidemiology, and End Results (SEER) data, and found that the age-adjusted incidence of most subtypes was $<1$ per 100,000 in the Hong Kong population, except for DLBCL (3.26) and plasma cell neoplasms (1.99). The incidences of follicular lymphoma and CLL were 0.75 and 0.52 , respectively, which was quite high compared to the incidences in our data (0.18 and 0.18). Rates in Asians from SEER data were generally intermediate compared to the rates in SEER Whites. Similar to our data, the incidence of extranodal $\mathrm{T} /$ NK-cell lymphoma, nasal type was much higher in Hong Kong (0.25) than in the United States (SEER White) (0.06). However, the number of Asian population in this analysis was relatively small compared to our data, with fewer than 10,000 cases in the Asian group, and survival data were lacking.

To our knowledge, this is the first population-based and subtype-specific survival analysis of hematologic malignancies in Asia. Comprehensive analysis based on subtypes defined by ICD-O-3 code is more useful than past population-based studies that divided lymphoid diseases in to broad categories such as 'non-Hodgkin's lymphoma' or 'leukemia' [20].

The multicenter retrospective analysis in Korea by Won et al. [21] previously showed that the overall survival rate of classical HL with a median follow-up of 30 months was $80.2 \%$. It did not include pediatric patients under the age of 16 years. In our KCCR data, the 5-year survival rate was $82.7 \%$ in 2008-2012. The overall survival outcome of HL was favorable. However, the survival rate of elderly patients over 65 years significantly decreased to $37 \%-54.4 \%$. The poor outcome of elderly patients may be due to unfavorable tumor biology and underlying comorbidities as well as the toxicity of current standard chemotherapy such as anthracyclines and bleomycin $[22,23]$. The introduction of less toxic but effective treatment would likely improve survival outcomes, especially in elderly patients, and the results of such treatment regimens could be evaluated in a future update of 



C

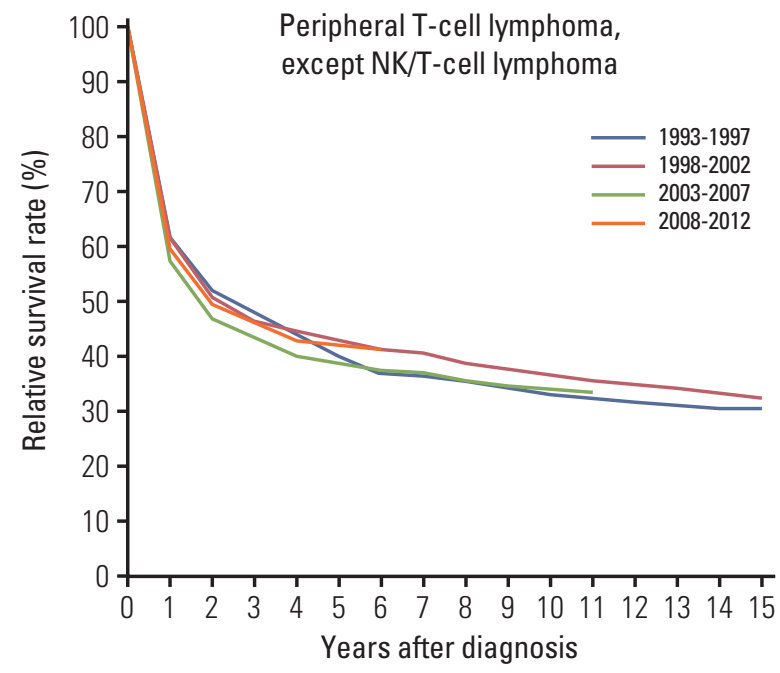

Fig. 3. Trend in relative survival rate of lymphoid malignances between 1993 and 2012 in Korea. ICD-O-3 codes are as follows. (A) Hodgkin's lymphoma 9659, 9650, 9661, 9662, 9651, 9663, 9664, 9665, 9667, 9652,9653, 9654, 9655. (B) Diffuse large B-cell lymphoma 9675, 9678, 9679, 9680, 96849684. (C) Multiple myeloma 9732. (D) Peripheral T-cell lymphoma, except NK/ T-cell lymphoma 9702, 9705, 9714, 9716, 9717. (Continued to the next page)

KCCR analyses.

We also observed marked survival improvement in patients with DLBCL between the pre-rituximab and postrituximab era: 5-year RSRs of 49.5\% to 61.5\% from 1993-1997 to 2008-2012, respectively. Rituximab, a monoclonal antibody that binds to CD20 on B cells and induces apoptosis of lymphoma cells, was approved in November 2003 by the Ministry of Food and Drug Safety (MFDS) in Korea. The influ- ence of rituximab-containing chemoimmunotherapy on DLBCL survival has been reported [24]. In addition, rituximab has been approved for various indications in NHLs other than DLBCL in the United States [25]. In our data, survival rates of follicular lymphoma also increased during the study period. With the broadened indication of rituximab in Korea for other NHLs such as mantle cell lymphoma and marginal zone lymphoma, we can expect better outcomes in 

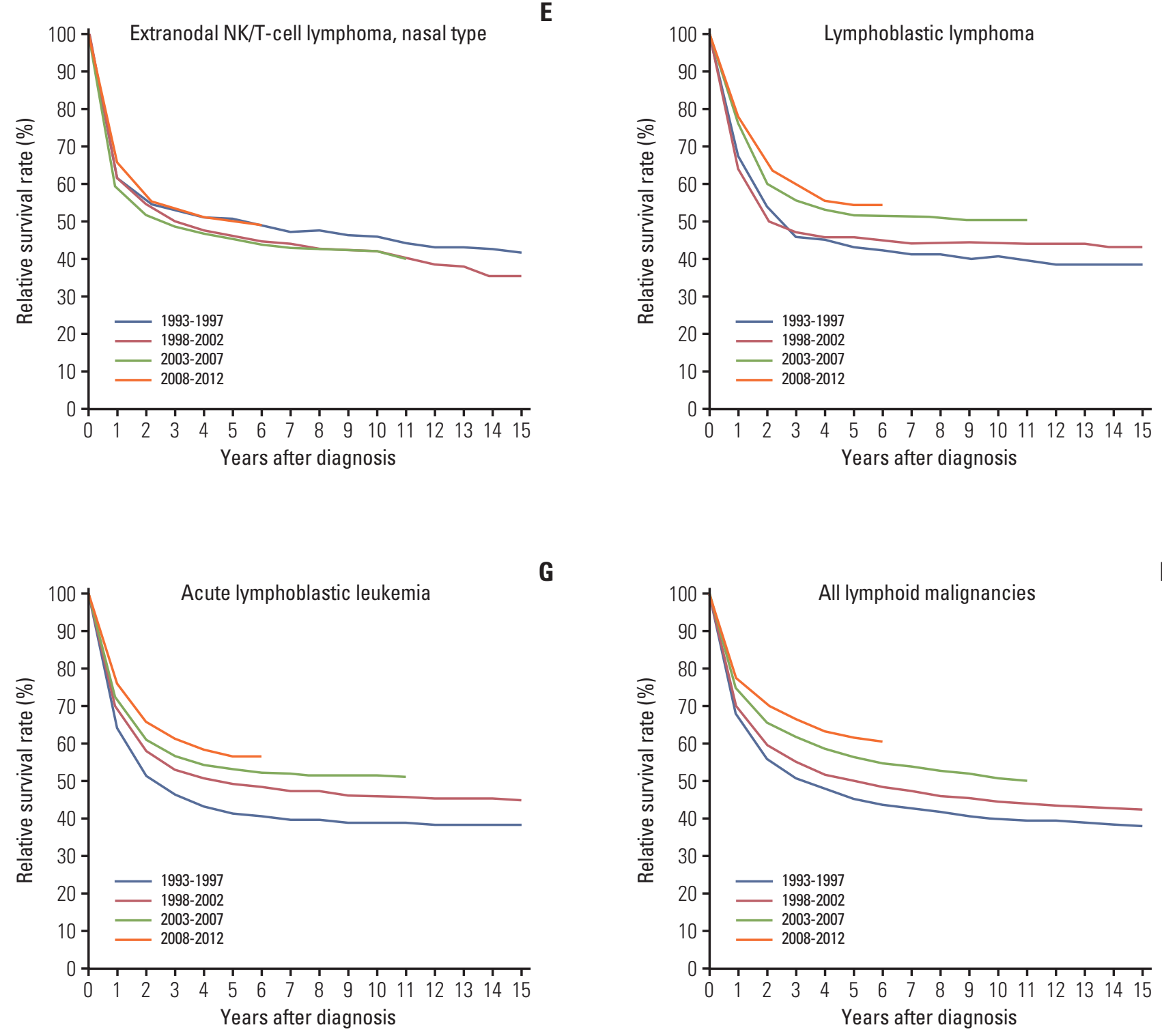

G



Fig. 3. (Continued from the previous page) (E) Extranodal NK/T-cell lymphoma, nasal type 9719. (F) Lymphoblastic lymphoma 9728, 9729, 9727. (G) Acute lymphoblastic leukemia 9836, 9837, 9835. (H) All lymphoid malignancies. ICD-O-3, International Classification of Diseases for Oncology, third edition.

the future data, although there were no significant improvements of survival in the present data.

For other T- and NK-cell lymphomas, except cutaneous T-cell lymphoma, there were no evident changes in survival rates during the study period (5-year RSR, $44.2 \%$ to $44.2 \%$ between 1993-1997 and 2008-2012, respectively). This result is in line with the unsatisfactory results of clinical trials for the disease categories, except for the paradigm shift in the management of extranodal NK/T-cell lymphoma, nasal type. In localized diseases, concomitant/sequential chemo- therapy and radiotherapy became standard therapy because radiotherapy alone was not adequate due to systemic relapse [26]. For advanced cases, systemic chemotherapy containing L-asparaginase and drugs unaffected by P-glycoprotein was indicated [27]. In subtype-specific analyses, survival of extranodal NK/T-cell lymphoma, nasal type, improved, revealing a 5-year RSR of $49.9 \%$ for all age groups in 2008$2012(\mathrm{n}=869)$ compared to $45.8 \%$ in $2003-2007(\mathrm{n}=670)$ and $46.5 \%$ in 1998-2002 ( $n=314$ ) (Fig. 3). The RSR in 1993-1997 seems to be superior, but this result might be due to a limi- 
Table 3. International comparison of age-standardized incidence rates of lymphoid malignancies

\begin{tabular}{|c|c|c|c|c|c|c|}
\hline & $\begin{array}{c}\text { Europe } \\
\text { (HAEMACARE) }\end{array}$ & $\begin{array}{l}\text { The United States } \\
\text { (SEER White) }\end{array}$ & $\begin{array}{l}\text { The United States } \\
\text { (SEER Asian) }\end{array}$ & Hong Kong ${ }^{b)}$ & Japan $^{\text {) }}$ & $\mathrm{KCCR}^{\mathrm{d})}$ \\
\hline & 2000-2002 & 2001-2010 & 2001-2010 & 2001-2010 & 2008 & 1999-2012 \\
\hline $\mathrm{HL}$ & 2.41 & 2.91 & 1.28 & 0.75 & 0.5 & 0.35 \\
\hline CLL/SLL & 3.79 & 4.75 & 1.06 & 0.52 & 0.1 & 0.18 \\
\hline DLBCL & 3.13 & 5.59 & 4.37 & 3.26 & 2.5 & 2.34 \\
\hline FL & 1.92 & 3.17 & 1.33 & 0.75 & 0.1 & 0.18 \\
\hline MCL & NA & 0.63 & 0.24 & 0.20 & 0.1 & 0.09 \\
\hline MZL & NA & 1.53 & 1.18 & 0.74 & 0.5 & 0.79 \\
\hline BL & NA & 0.42 & 0.28 & 0.27 & 0.12 & 0.16 \\
\hline PCN & 4.62 & 4.03 & 2.54 & 1.99 & 1.5 & 1.30 \\
\hline Extranodal NK/T & NA & 0.06 & 0.12 & 0.25 & 0.08 & 0.22 \\
\hline ALCL & NA & 0.32 & 0.20 & 0.18 & 0.11 & 0.11 \\
\hline AITL & NA & 0.10 & 0.13 & 0.12 & 0.12 & 0.10 \\
\hline PTCL-NOS & NA & 0.30 & 0.28 & 0.27 & 0.25 & 0.26 \\
\hline ALL/LBL & $1.42^{\mathrm{e})}$ & \multicolumn{2}{|c|}{$1.7^{\mathrm{f})}$} & NA & 1.1 & 1.22 \\
\hline All lymphoid & 24.50 & 28.55 & 16.11 & 11.22 & NA & 8.41 \\
\hline
\end{tabular}

All rates expressed per 100,000 person-years. SEER, Surveillance, Epidemiology, and End Results; KCCR, Korea Central Cancer Registry; HL, Hodgkin's lymphoma; CLL/SLL, chronic lymphocytic leukemia/small lymphocytic lymphoma; DLBCL, diffuse large B-cell lymphoma; FL, follicular lymphoma; MCL, mantle cell lymphoma; NA, not available; MZL, marginal zone lymphoma; BL, Burkitt's lymphoma / leukemia; PCN, plasma cell neoplasm; NK, natural killer; ALCL, anaplastic large cell lymphoma; AITL, angioimmunoblastic T-cell lymphoma; PTCL-NOS, peripheral T-cell lymphoma, not otherwise specified; ALL, acute lymphoblastic leukemia; LBL, lymphoblastic lymphoma. ${ }^{a}$ Data from European HAEMACARE project [10], b)Ageadjusted to the World Health Organization's World Standard Population (2000-2025) [21], c)Age-standardized to the world population. Estimated values from the published figures [22], ${ }^{\mathrm{d}}$ Weighted averages of crude age-specific rates, calculated using Segi's world standard population (presented data), ${ }^{\mathrm{e}}$ This rate includes lymphoblastic lymphomas, ${ }^{\mathrm{f}}$ From SEER data including all ethnic groups. Age-adjusted to the 2,000 U.S. standard population [23].

tation of the registry; the registry did not cover the entire population at that time, so the number of cases was relatively insufficient (153 cases in 1993-1997). The survival benefits from the current therapy for extranodal NK/T-cell lymphoma, nasal type, needs to be confirmed in future analysis.

The standard treatment of MM also changed during the study period. Autologous stem cell transplantation was introduced in early 1990s. In addition, thalidomide, bortezomib, and lenalidomide were approved by MFDS in April 2006, March 2006, and December 2009, respectively. We found that the 5-year RSR of patients with plasma cell neoplasms changed from 20.2\% to 36.9\% from 1993 to 2012, respectively. This rate is still unsatisfactory, and it is lower than the RSR in the United States (48.5\%) between 2006 and 2012 [14], but an increasing trend in survival rates in Korea is encouraging for such an 'incurable disease.'

The survival rates of acute lymphoblastic leukemia/lymphoma showed improving trends based on the year of diagnosis, with 5-year RSR of all age groups reaching 56.3\% in
2008-2012. Age at diagnosis significantly influenced the survival of this disease. The 5-year RSR in pediatric patients (aged 0-14 years) is $82.7 \%$, but it falls dramatically in young adults (50.1\%, aged $15-34$ years) and adults (33\%, aged $35-49$ years). Poor prognosis of adult acute lymphoblastic leukemia /lymphoma is historically well known, and the factors associated with this difference in outcome include the poorer biology of the leukemia, the lower compliance of patients (physically and emotionally), differences in the therapeutic approaches, and the lower rates of enrollment in clinical trials [28-30]. Efforts to improve outcomes in adults include development of pediatric-inspired chemotherapy protocols for young adults and the combination of tyrosine kinase inhibitors, such as imatinib and dasatinib with conventional chemotherapy for Philadelphia-positive disease. Welldesigned and clinical trial-based treatment protocols for adult patients should be established in Korea.

We reported the subtype-specific incidence and survival of lymphoid malignancies. Our research showed increasing 
incidence and survival rates based on the year of diagnosis in most subtypes. In addition, the survival rates of most subtypes (except for indolent disease) decreased dramatically with age. The strength of our study is that these data were analyzed in clinically meaningful disease categories. Additionally, this is a good example for refining and utilizing data from pre-existing cancer registry. If we can integrate more detailed information such as immunophenotypes, genetic abnormalities, and treatment information, to the registry, the quality of data on hematologic malignancies will improve. The qualified registry can provide practical evidence to determine whether advances in diagnosis and treatment can improve cancer survival.

\section{Electronic Supplementary Material}

Supplementary materials are available at Cancer Research and Treatment website (http:// www.e-crt.org).

\section{Conflicts of Interest}

Conflict of interest relevant to this article was not reported.

\section{Acknowledgments}

This work was supported by a research grant from the National Cancer Center (1610200).

\section{References}

1. Torre LA, Bray F, Siegel RL, Ferlay J, Lortet-Tieulent J, Jemal A. Global cancer statistics, 2012. CA Cancer J Clin. 2015;65: 87-108.

2. Swerdlow SH, Campo E, Harris NL, Jaffe ES, Pileri SA, Stein $\mathrm{H}$, et al. WHO classification of tumours of haematopoietic and lymphoid tissues. 4th ed. Lyon: IARC Press; 2008.

3. Muller AM, Ihorst G, Mertelsmann R, Engelhardt M. Epidemiology of non-Hodgkin's lymphoma (NHL): trends, geographic distribution, and etiology. Ann Hematol. 2005;84:1-12.

4. Rudiger T, Weisenburger DD, Anderson JR, Armitage JO, Diebold J, MacLennan KA, et al. Peripheral T-cell lymphoma (excluding anaplastic large-cell lymphoma): results from the Non-Hodgkin's Lymphoma Classification Project. Ann Oncol. 2002;13:140-9.

5. Ohshima K, Suzumiya J, Kikuchi M. The World Health Organization classification of malignant lymphoma: incidence and clinical prognosis in HTLV-1-endemic area of Fukuoka. Pathol Int. 2002;52:1-12.

6. Harris NL, Jaffe ES, Stein H, Banks PM, Chan JK, Cleary ML, et al. A revised European-American classification of lymphoid neoplasms: a proposal from the International Lymphoma Study Group. Blood. 1994;84:1361-92.

7. Bennett JM, Catovsky D, Daniel MT, Flandrin G, Galton DA, Gralnick HR, et al. Proposals for the classification of chronic (mature) B and T lymphoid leukaemias. French-AmericanBritish (FAB) Cooperative Group. J Clin Pathol. 1989;42: 567-84.

8. Bennett JM, Catovsky D, Daniel MT, Flandrin G, Galton DA, Gralnick HR, et al. Proposals for the classification of the acute leukaemias. French-American-British (FAB) co-operative group. Br J Haematol. 1976;33:451-8.

9. Percy C, Fritz A, Jack A, Shanmugarathan S, Sobin L, Parkin $\mathrm{DM}$, et al. International classification of diseases for oncology (ICD-O). 3rd ed. Geneva: World Health Organization; 2000.

10. Marcos-Gragera R, Allemani C, Tereanu C, De Angelis R,
Capocaccia R, Maynadie M, et al. Survival of European patients diagnosed with lymphoid neoplasms in 2000-2002: results of the HAEMACARE project. Haematologica. 2011;96: 720-8.

11. Sant M, Allemani C, Tereanu C, De Angelis R, Capocaccia R, Visser $\mathrm{O}$, et al. Incidence of hematologic malignancies in Europe by morphologic subtype: results of the HAEMACARE project. Blood. 2010;116:3724-34.

12. Park HJ, Park EH, Jung KW, Kong HJ, Won YJ, Lee JY, et al. Statistics of hematologic malignancies in Korea: incidence, prevalence and survival rates from 1999 to 2008. Korean J Hematol. 2012;47:28-38.

13. Segi M. Cancer mortality for selected sites in 24 countrues (1950-1957). Sendai: Tohoku University School of Medicine; 1960.

14. Howlader N, Noone AM, Krapcho M, Miller D, Bishop K, Altekruse SF, et al. SEER Cancer Statistics Review, 1975-2013 [Internet]. Bethesda, MD: National Cancer Institute; 2015 [cited 2016 Apr 1]. Available from: http:// seer.cancer.gov/csr/1975_ $2013 /$.

15. Ederer F, Axtell LM, Cutler SJ. The relative survival rate: a statistical methodology. Natl Cancer Inst Monogr. 1961;6:101-21.

16. Dickman PW, Sloggett A, Hills M, Hakulinen T. Regression models for relative survival. Stat Med. 2004;23:51-64.

17. Ederer F, Heise H. Instructions to IBM 650 programmers in processing survival computations. Methodological note No. 10. End results evaluation section. Bethesda, MD: National Cancer Institute; 1959.

18. Bassig BA, Au WY, Mang O, Ngan R, Morton LM, Ip DK, et al. Subtype-specific incidence rates of lymphoid malignancies in Hong Kong compared to the United States, 2001-2010. Cancer Epidemiol. 2016;42:15-23.

19. Chihara D, Ito H, Matsuda T, Shibata A, Katsumi A, Nakamura $S$, et al. Differences in incidence and trends of haematological malignancies in Japan and the United States. Br J 
Haematol. 2014;164:536-45.

20. Jung KW, Won YJ, Kong HJ, Oh CM, Cho H, Lee DH, et al. Cancer statistics in Korea: incidence, mortality, survival, and prevalence in 2012. Cancer Res Treat. 2015;47:127-41.

21. Won YW, Kwon JH, Lee SI, Oh SY, Kim WS, Kim SJ, et al. Clinical features and outcomes of Hodgkin's lymphoma in Korea: Consortium for Improving Survival of Lymphoma (CISL). Ann Hematol. 2012;91:223-33.

22. Jarrett RF, Stark GL, White J, Angus B, Alexander FE, Krajewski AS, et al. Impact of tumor Epstein-Barr virus status on presenting features and outcome in age-defined subgroups of patients with classic Hodgkin lymphoma: a population-based study. Blood. 2005;106:2444-51.

23. Engert A, Ballova V, Haverkamp H, Pfistner B, Josting A, Duhmke E, et al. Hodgkin's lymphoma in elderly patients: a comprehensive retrospective analysis from the German Hodgkin's Study Group. J Clin Oncol. 2005;23:5052-60.

24. Flowers CR, Fedewa SA, Chen AY, Nastoupil LJ, Lipscomb J, Brawley OW, et al. Disparities in the early adoption of chemoimmunotherapy for diffuse large B-cell lymphoma in the United States. Cancer Epidemiol Biomarkers Prev. 2012;21:
1520-30.

25. Bruce CJ. Rituxan anniversary: 10 years of progress. Oncol Bus Rev. 2007;18-9.

26. Kim SJ, Kim K, Kim BS, Kim CY, Suh C, Huh J, et al. Phase II trial of concurrent radiation and weekly cisplatin followed by VIPD chemotherapy in newly diagnosed, stage IE to IIE, nasal, extranodal NK/T-Cell Lymphoma: Consortium for Improving Survival of Lymphoma study. J Clin Oncol. 2009;27:6027-32.

27. Kwong YL, Kim WS, Lim ST, Kim SJ, Tang T, Tse E, et al. SMILE for natural killer/T-cell lymphoma: analysis of safety and efficacy from the Asia Lymphoma Study Group. Blood. 2012;120:2973-80.

28. Moorman AV, Chilton L, Wilkinson J, Ensor HM, Bown N, Proctor SJ. A population-based cytogenetic study of adults with acute lymphoblastic leukemia. Blood. 2010;115:206-14.

29. Veal GJ, Hartford CM, Stewart CF. Clinical pharmacology in the adolescent oncology patient. J Clin Oncol. 2010;28:4790-9.

30. Bleyer A, Budd T, Montello M. Adolescents and young adults with cancer: the scope of the problem and criticality of clinical trials. Cancer. 2006;107(7 Suppl):1645-55. 